\title{
Mitral valve replacement in the baboon (Papio ursinus) and the human with the University of Stellenbosch mitral valve prosthesis ${ }^{1}$
}

\author{
PIETER M. BAR NARD AND J.J. HEYDENRYCH \\ From the Department of Cardiothoracic Surgery, Karl Bremer Hospital and the University of Stellenbosch, \\ Bellville, South Africa
}

\begin{abstract}
To study the problem of thromboembolism that occurs following the use of prosthetic valves, the mitral valve was replaced in 20 Cape Chagma baboons with the University of Stellenbosch (U.S.B.) mitral valve prosthesis. In the absence of anticoagulants massive thrombus invariably formed on the metal portion of the prosthesis when the latter was left uncovered by material that allows for tissue ingrowth. Smooth, fairly well controlled tissue ingrowth occurred when the prosthetic ring was covered by Dacron velour material. Massive thrombus formation was never encountered although small fibrin thrombi, a potential source of emboli, became loosely attached to the Dacron velour covered prosthetic ring during the first eight post-operative weeks. Thereafter the smooth ingrowth of living tissue into the prosthesis appears capable of preventing thromboembolism. The clinical use of anticoagulants during the initial 3-4 post-operative months is recommended in view of our experimental findings and clinical experience of early embolism that occurred in 3 of 10 patients in whom the U.S.B. Dacron velour covered prosthesis was used in the absence of anticoagulants. This is the first reported study in which a sub-human primate was used to study the problem of thromboembolism associated with prosthetic valve replacement. The baboon can be highly recommended for this purpose.
\end{abstract}

Thromboembolism, in the human, remains a major complication following prosthetic mitral valve replacement. In several reported series (Björk and Malers, 1964; Cooley, Bloodwell, Beall, Gill, and Hallman, 1966; Schrire and Barnard, 1966 ; Starr, Herr, and Wood, 1967), using different types of prosthesis, the incidence varied between $10 \%$ and $75 \%$.

To study the problem of thromboembolism we selected the Cape Chagma baboon (Papio ursinus) as the experimental animal. As a sub-human primate possessing the same ABO blood groups as the human, we presumed that the baboon would be more suitable than the dog (Starr, 1960; Den Otter, 1968 ; Barnard and Heydenrych, 1968) or calf (Braunwald and Bonchek, 1967) previously used as the experimental animal for this purpose.

Our earlier experience using mongrel dogs for prosthetic tricuspid valve replacement (Barnard and Heydenrych, 1968), and more recently for prosthetic mitral valve replacement, revealed a marked tendency for infective thrombi to occur

1Paper presented at the Sixth Biennial Congress of the Southern Africa Cardiac Society, Johannesburg, 5 August 1968 despite the use of antibiotics. Long-term survival could only rarely be obtained, and the presence of septicaemia complicated the interpretation of the results.

\section{EXPERIMENTAL STUDY}

Twenty baboons, weighing 18-24 kg., underwent mitral valve replacement with the University of Stellenbosch (U.S.B.) mitral valve prosthesis. The silastic $^{2}$ disc incorporates a stainless steel ring, and in the latest design a perforated nylon plate, and is contained in a highly polished stainless steel cage. The prosthetic ring is covered with Dacron velour (Fig. 1).

Group I consisted of five animals used as a control group in which the prosthetic ring was not covered by Dacron velour material, thus exposing bare metal to the blood stream.

Group II consisted of 15 animals with the prosthetic ring completely covered with Dacron velour material.

\section{OPERATIVE TECHNIQUE}

The wild animals are kept in a primate colony in the hospital grounds. Following an injection of phen-

2Supplied by Dow Corning, Midland, Michigan, U.S.A. 


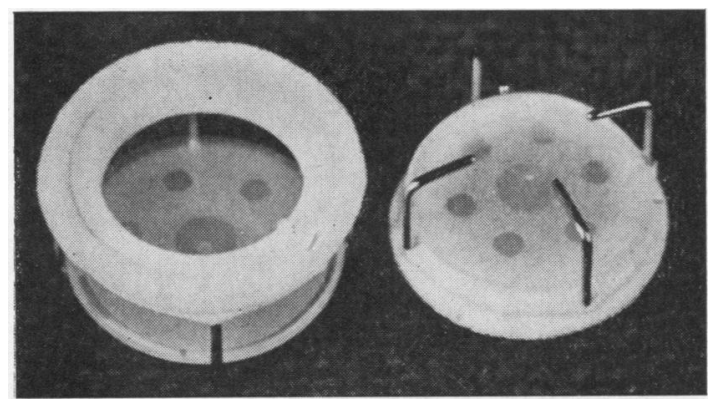

FIG. 1. The latest design of the U.S.B. mitral valve prosthesis. See text.

cyclidine (Sernylan), $1 \mathrm{mg} . / \mathrm{kg}$. bodyweight intramuscularly, the animals could easily be transported from the primate colony to the theatre. The baboons were anaesthetized with suxamethonium chloride (Scoline), $2 \mathrm{mg} . / \mathrm{kg}$. bodyweight intramuscularly, supplemented with nitrous oxide and oxygen through an endotracheal tube. During bypass, 0.25 to $0.5 \%$ halothane (Fluothane) was used as necessary.

Under sterile conditions the right femoral artery was cannulated for the return of oxygenated blood from the heart/lung machine. Heparin, $2 \mathrm{mg}$. $/ \mathrm{kg}$. bodyweight, was given intravenously to prevent the blood from clotting. The left femoral vein was cannulated for monitoring the central venous pressure. Mean intra-arterial pressures were obtained by means of a plastic needle inserted into the left femoral artery. Immediately before, during, and for 2-4 hours following bypass, the haematocrit, $p \mathrm{H}, \mathrm{Po}_{2}$, arterial oxygen saturation, $\mathrm{PcO}_{2}$, standard bicarbonate, base excess, serum potassium, sodium, and chloride were regularly determined and corrected as necessary. The urinary output was measured via an indwelling Foley's catheter. An electrocardiographic tracing was obtained at regular intervals.

A left thoracotomy through the bed of the fourth rib was used. Venous return was through a single $\frac{1}{4}$-in. inside diameter catheter inserted into the outflow tract of the right ventricle. A low-prime, disposable bubble oxygenator was used, primed with baboon typed whole blood and diluted $25 \%$ with Ringer's lactate solution. High flow rates, averaging 120-130 $\mathrm{ml} . / \mathrm{kg}$. bodyweight $/$ minute, and mild hypothermia to $32^{\circ} \mathrm{C}$. rectally were used in all cases. A left ventricular vent was inserted and the left atrial appendage was opened longitudinally with the incision extending to the left pulmonary veins on full bypass after the heart had been electrically fibrillated.

The mitral valve leaflets, chordae tendineae, and papillary muscles were excised, leaving a $2 \mathrm{~mm}$. rim of valve tissue attached to the mitral annulus. A $14 \mathrm{~mm}$. inside diameter U.S.B. prosthesis was inserted into the mitral annulus with interrupted horizontal 3-0 Tefdek sutures. Usually a total of 12 sutures were needed for secure fixation of the prosthesis. The left atrium was closed following evacuation of air and the heart was defibrillated with a D.C. defibrillator once the body temperature had reached $37^{\circ} \mathrm{C}$. The vent and venous cannula were removed and protamine sulphate, $1.5 \mathrm{ml} . / \mathrm{kg}$. bodyweight, was given to restore the normal clotting ability of the blood. The right femoral artery was ligated following removal of the cannula as these animals have excellent collateral circulation to the hind legs. A drainage tube was inserted into the left pleural cavity and usually removed after 2-4 hours. The chest was closed and the endotracheal tube was removed as soon as the animal had recovered from the effects of anaesthesia. Typed ACD baboon blood was given in the immediate postoperative period according to the venous pressure and blood pressure determinations. Following removal of the venous and arterial pressure lines and the Foley's catheter, the animal was cared for in a specially designed iron cage and post-operative room. Cloxacillin, $1 \mathrm{~g}$., and streptomycin, $0.5 \mathrm{~g}$., were given intramuscularly every 12 hours for five days. Digitalis and anticoagulants were not administered to these animals. The majority of the animals operated upon during the morning were eating fruit and drinking water the same afternoon. In sharp contrast to our earlier dog experiments, no bleeding tendencies were encountered in the postoperative period.

\section{RESULTS}

GROUP I All five animals survived the operation. Three baboons died between two and four weeks post-operatively from massive thrombus formation on the prosthesis, more prevalent on the atrial side (Fig. 2). Bacteriological studies from these thrombi revealed no growth. Two animals died on

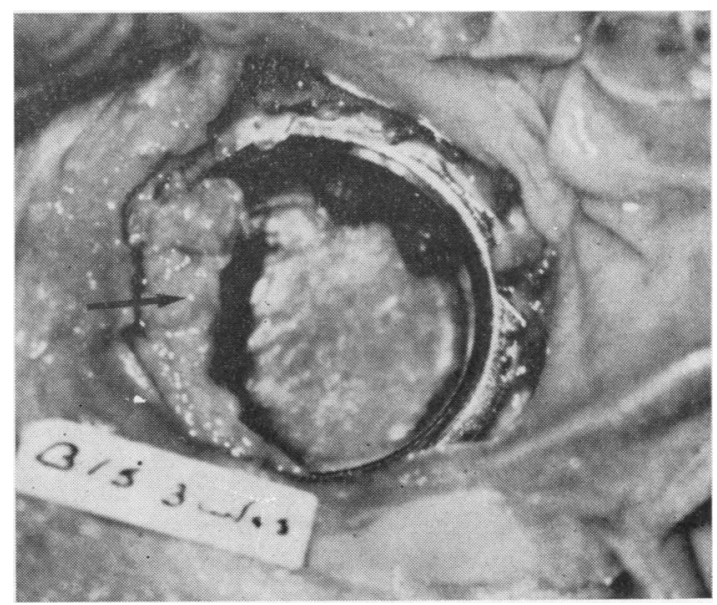

FIG. 2. Large antemortem thrombus (arrow) present on atrial side of the prosthesis. 
the third and fifth days from pneumonia and diarrhoea respectively. No thrombi were present on these valves.

GROUP II Two baboons died within 72 hours after the operation from collapse of the lungs with pneumonia. Thirteen baboons survived the operation. Of these, five succumbed from diarrhoea in the primate colony between the second and fourth postoperative months. Six animals were sacrificed at intervals ranging from two weeks to four months postoperatively. Two animals are presently being kept as long-term survivors to be sacrificed at a later stage.

Those animals in group II sacrificed at two weeks showed a thin fibrin deposit partially, and in some instances completely, covering the prosthetic ring with a minimum of small fibrin thrombi adherent to the valve opening (Fig. 3). No massive

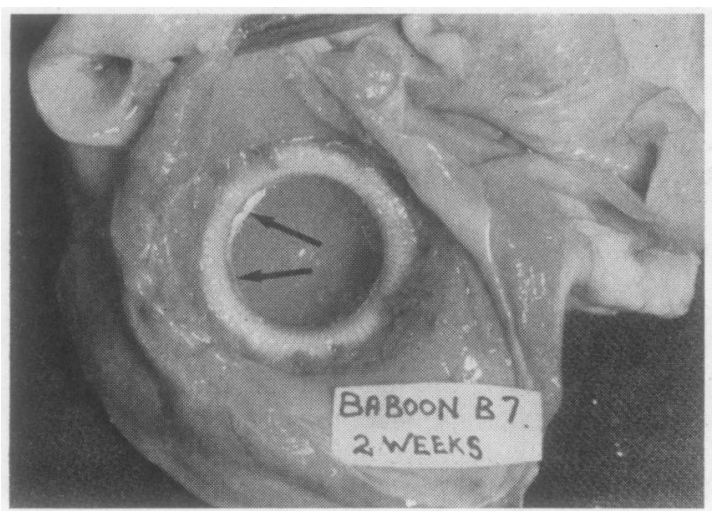

FIG. 3. Thin fibrin deposit covering the prosthesis with small fibrin thrombi (arrows) present in valve opening as seen from the left atrium.

thrombi were encountered. Animals sacrificed between two and four weeks post-operatively showed identical findings with, however, a firmer ingrowth of tissue into the Dacron material. Between five and eight weeks the Dacron material was covered by a glistening smooth ingrowth of tissue. Irregular fibrin thrombi loosely attached to the tissue layer, however, were present in the valve ring (Figs 4, 5 , and 6). Cultures obtained from this material revealed no growth. Animals that were sacrificed or succumbed between three and four months postoperatively were free of any thrombus formation (Figs 7, 8, and 9). A smooth although slightly irregular tissue, built up in one case, was present in the valve opening as well (Figs 7 and 8). The

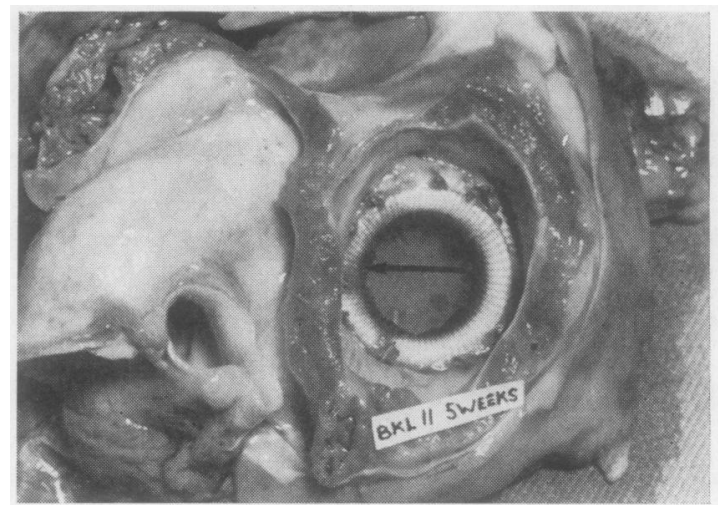

FIG. 4. Smooth ingrowth of tissue into the prosthetic covering with irregular fibrin thrombi (arrow) attached to the valve opening as seen from the left atrium.

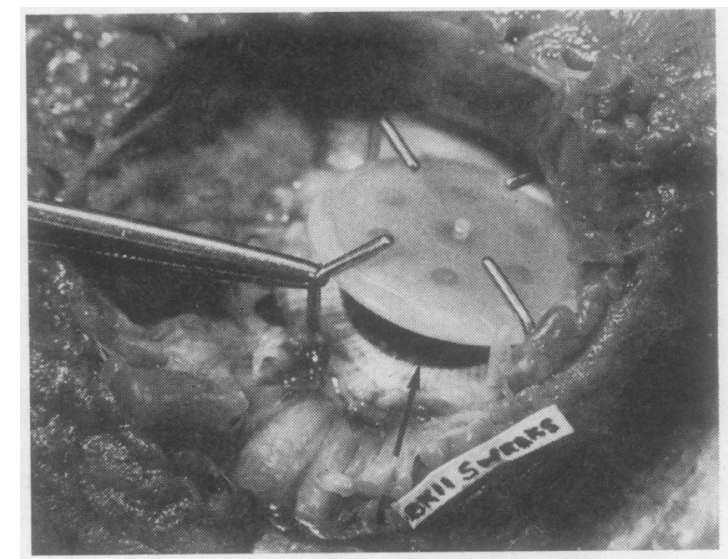

FIG. 5. The same as in Fig. 4 as seen from the left ventricle.

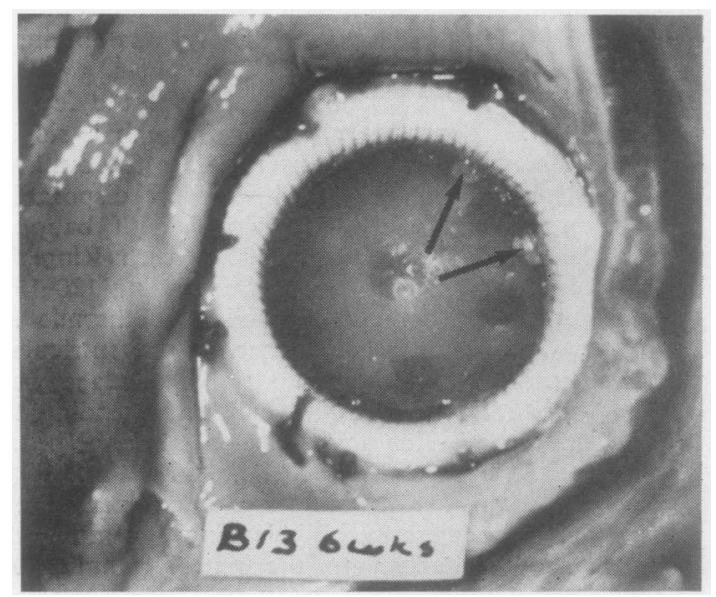

FIG. 6. Irregular fibrin thrombi (arrows) are attached to the valve opening as seen from the left atrium. 


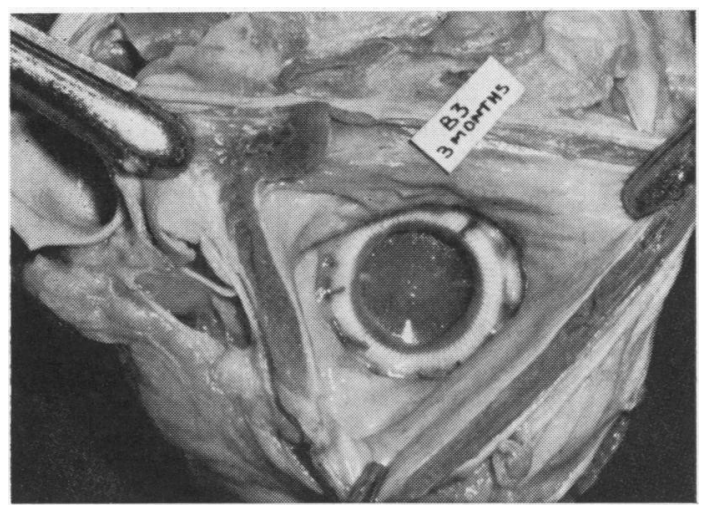

FIG. 7. Smooth, slightly irregular tissue ingrowth into valve ring with absence of fibrin thrombi as seen from the left atrium.

thickness of the tissue ingrowth varied from 0.3 to $0.4 \mathrm{~mm}$., covering the atrial and ventricular aspects of the prosthesis to $0.4-1.3 \mathrm{~mm}$. in the prosthetic opening. Histopathological studies of the tissue ingrowth into the Dacron material revealed this to consist of fibrin with an ingrowth of fibroblasts covered by an endothelial layer of cells.

HUMan Mitral VALVE RePlacement Following cardiac catheterization and angiocardiographic confirmation of the adequate functioning of the U.S.B. prosthesis in these animals, it was decided to use the valve clinically. The results of testing this prosthesis in a pulse duplicator and accelerated fatigue testing had previously been reported (Barnard, Heydenrych, Mead, and Cloete, 1967).

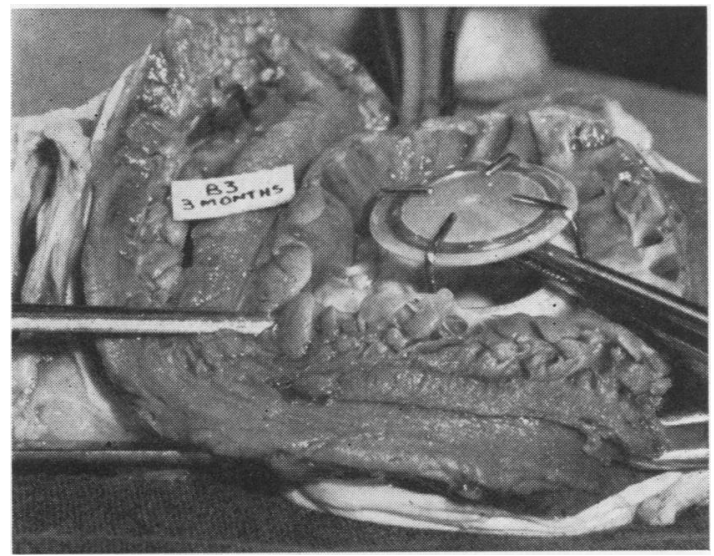

FIG. 8. The same as in Fig. 7 as seen from the left ventricle.
The mitral valve was replaced through a right thoracotomy in 12 patients ranging in age from 9 to 48 years. All patients were in functional class III or IV according to the classification of the New York Heart Association.

Two patients died on the fifth and fourteenth post-operative days respectively with a hospital mortality of $16.6 \%$. These deaths were due to progressive cardiac failure and pneumonia in both cases, accompanied by deep jaundice in one. Necropsies were performed in both cases. No gross thrombus formation on the prosthesis was encountered. One of these patients received no

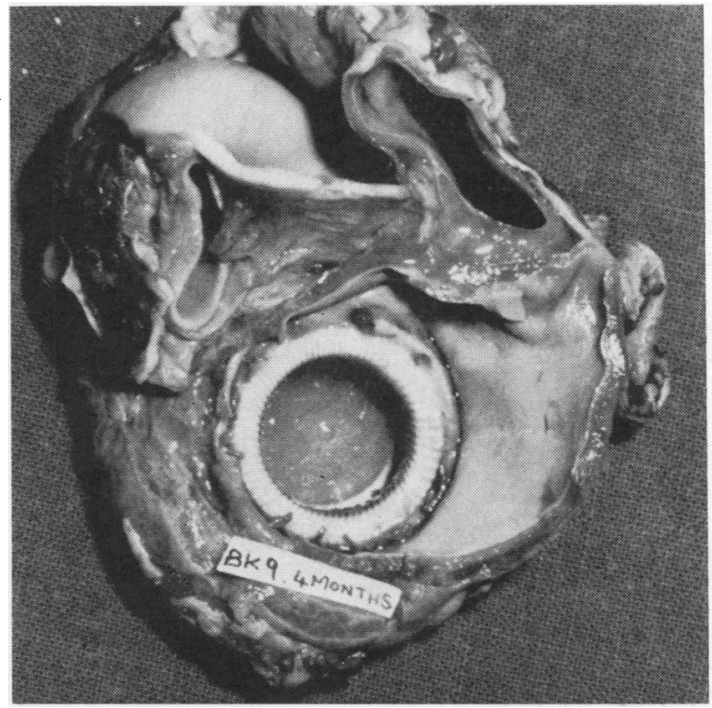

FIG. 9. Glistening smooth tissue ingrowth into the Dacron material with absence of thrombi as seen from the left atrium

anticoagulants, and at two weeks the valve showed a picture identical to that observed in the baboon (Figs 10 and 11). The Dacron material was covered by a thin fibrin layer with small fibrin thrombi attached to the valve opening.

Ten patients were discharged after an average hospital stay of three weeks. There have been no late deaths so far. Three patients were recatheterized from three to five months post-operatively. Pulmonary pressures and cardiac outputs had returned to normal. No abnormal end-diastolic gradient at rest was present across the smaller prosthesis (inner diameter $20 \mathrm{~mm}$.) (Fig. 12) or the largest size prosthesis (inner diameter $23 \mathrm{~mm}$.). Recatheterization studies in patients with the medium size prosthesis (inner diameter $22 \mathrm{~mm}$.) 


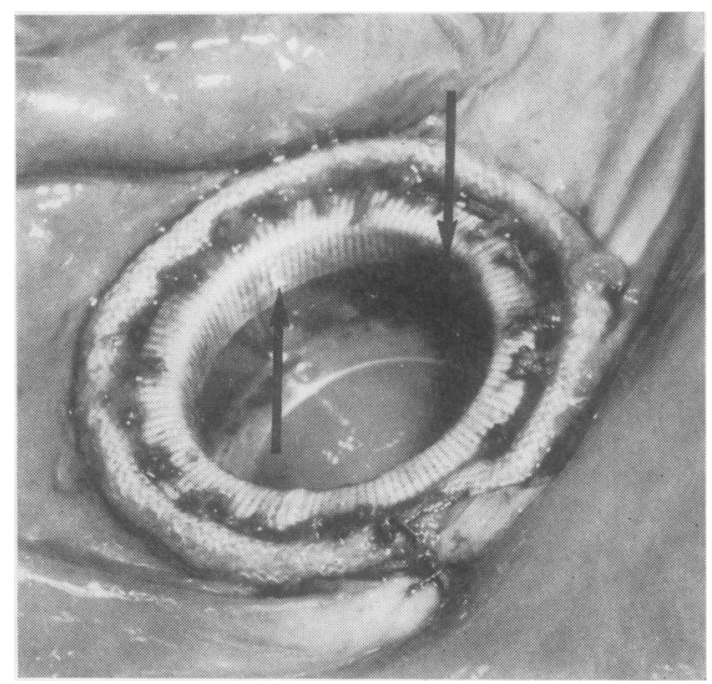

FIG. 10. Necropsy specimen as seen from the left atrium of patient who died after 2 weeks. Small fibrin thrombi (arrows) are present in the valve opening.

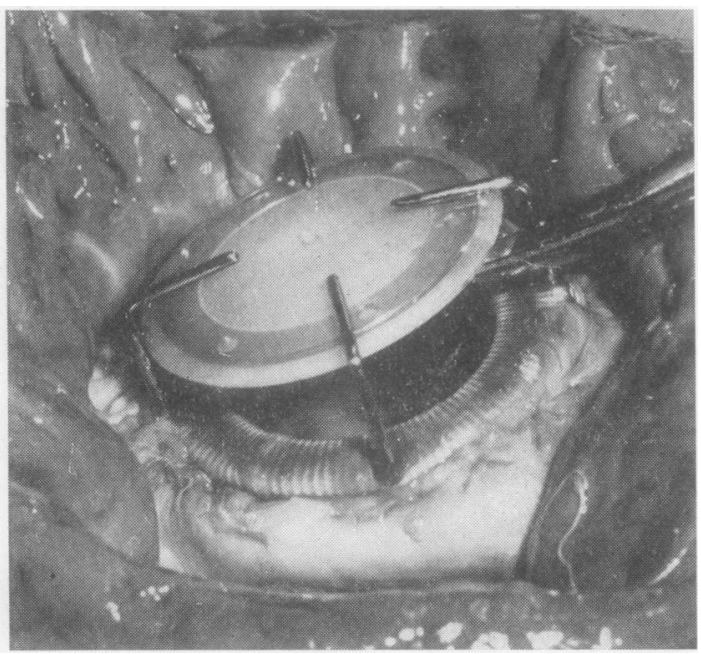

FIG. 11. The same as in Fig. 10 as seen from the left ventricle.

have not been performed. Cineangiography following left ventricular injection revealed no mitral incompetence (Figs 13 and 14). The heart decreased in size in all cases, and in some instances this decrease was pronounced (Fig. 15).

POST-OPERATIVE EMBOLISM Single episodes of cerebral embolism were encountered in three of the 10 surviving patients for an incidence of $30 \%$. These three patients had received no anticoagu- lants, and in two patients in atrial fibrillation the embolic episodes occurred on the fourteenth and fifteenth post-operative days and in one patient in sinus rhythm during the seventh post-operative week. None of these attacks was fatal, with sub- $\Omega$ sequent complete recovery in two patients and a gradual improvement in the third patient. Seven $\overrightarrow{0}$ patients were placed on long-term anticoagulant therapy (warfarin sodium) started on the fourth $\vec{\omega}$ post-operative day. No embolic episodes were encountered in these patients during follow-up $\times$ periods ranging from four to 12 months post- $\underset{\perp}{N}$ operatively.

\section{DISCUSSION}

In our baboon experiments with the valve opening uncovered by a material that allows for tissue in- $c$ growth, massive thrombus formation occurred in all surviving cases on the left atrial side in the absence of infection. Thrombus accumulated on

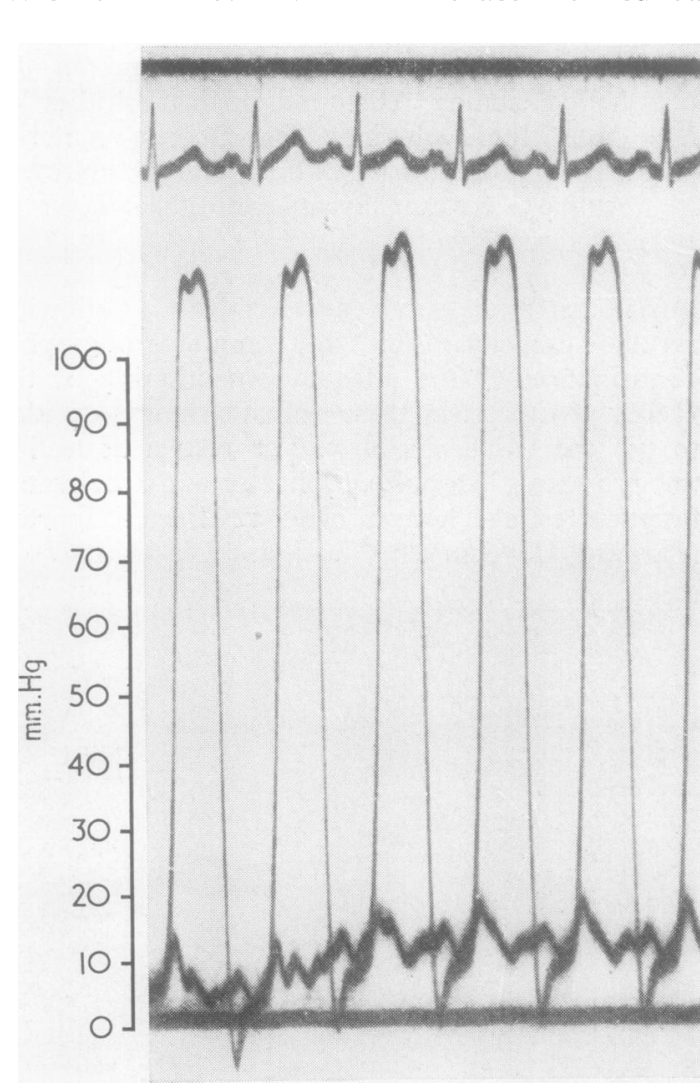

FIG. 12. Simultaneous tracings of pulmonary wedge pressure and left ventricular pressure curves showing no abnormal end-diastolic gradient across the mitral prosthesis. 


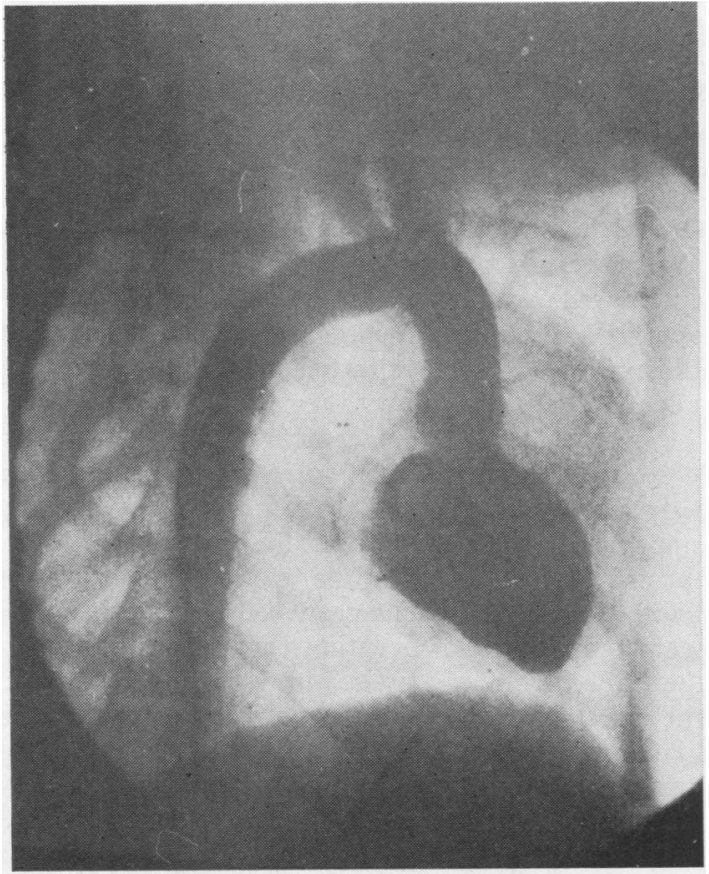

FIG. 13. Left ventricular angiography during diastole with the U.S.B. prosthesis in the mitral position.

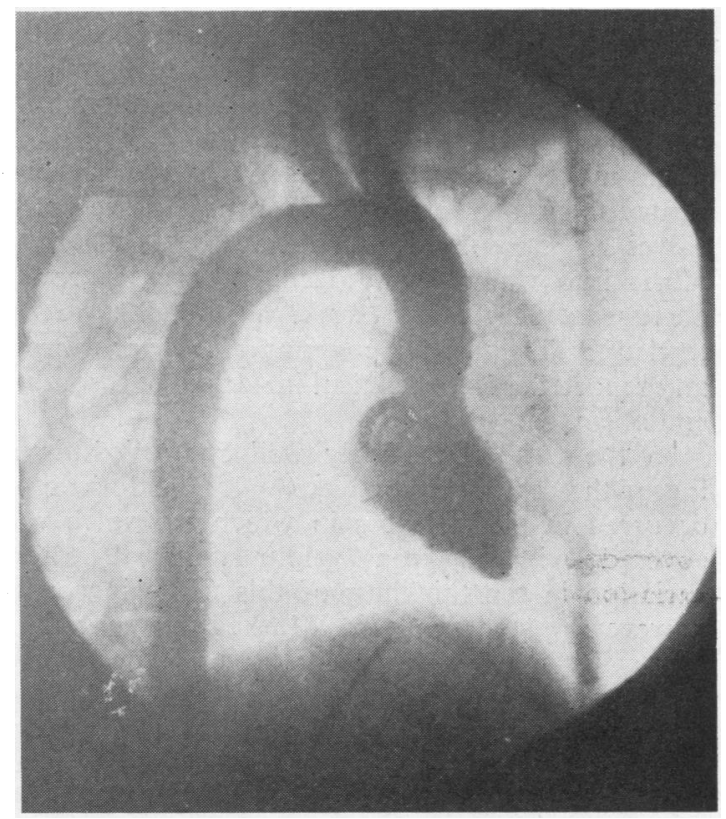

FIG. 14. The same as in Fig. 13 during systole with complete absence of mitral regurgitation.

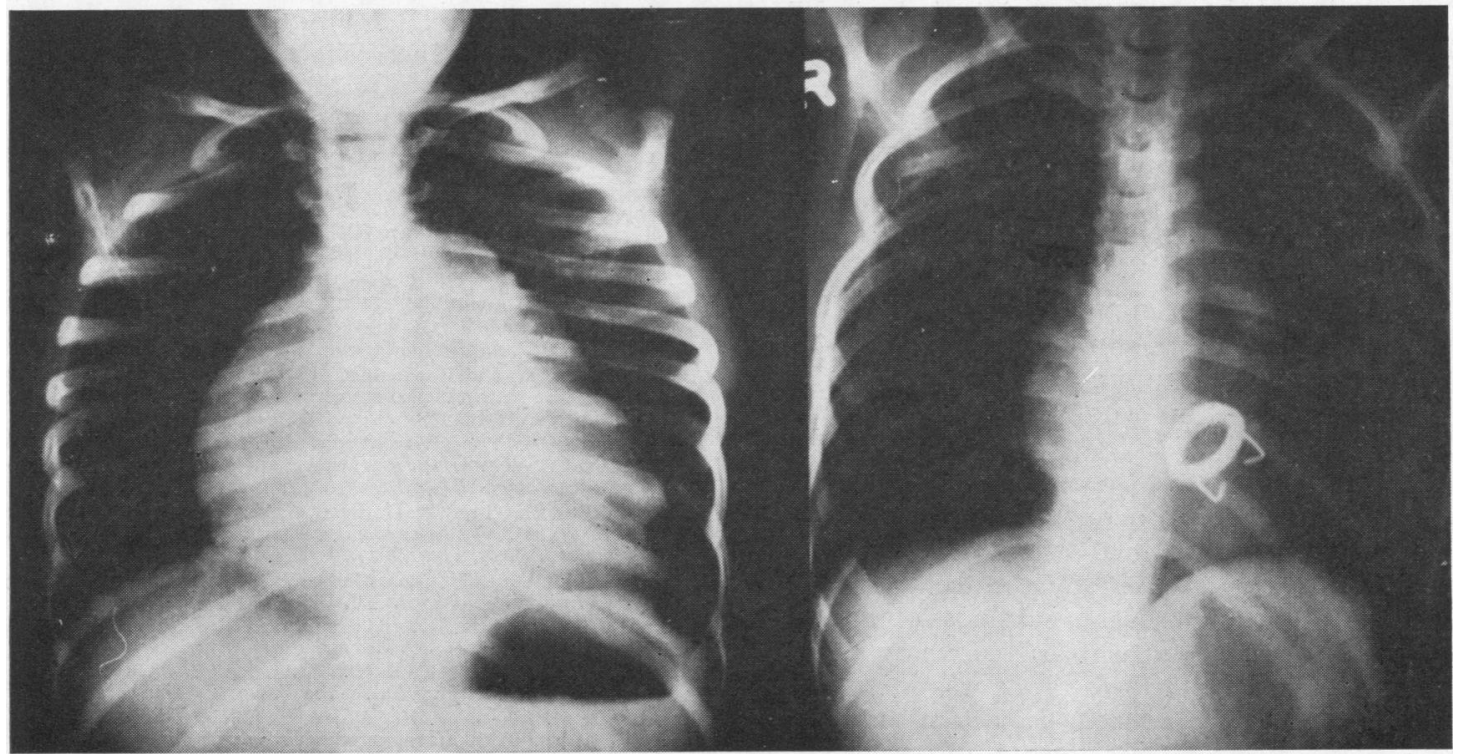

FIG. 15. Pre-operative chest radiograph (left) of a 10-year-old patient showing gross cardiomegaly, and postoperative radiograph (right) showing pronounced reduction in heart size one month following prosthetic valve replacement. 
the exposed metal ring at the tissue-metal interface with eventual extension through the prosthetic opening to the ventricular side. This rendered the disc immobile and resulted in the death of the animal. Other workers have reported similar findings (Braunwald and Bonchek, 1966).

Braunwald and Bonchek (1967) effectively prevented thrombus formation on prosthetic valves in calves by covering the prosthesis with a porous fabric into which an autogenous tissue ingrowth occurred. Recently Starr et al. (1967) have extended the Teflon cloth covering of their prosthesis, and reported a lower clinical incidence of thromboembolism.

In the baboon, a fairly well controlled tissue ingrowth, smoothly covered by endothelium, occurred in all instances in which the valve was covered with Dacron velour material. Slight variation in the thickness of this tissue ingrowth, however, was encountered. Marked overgrowth of tissue that could result in gross mitral stenosis and massive thrombus formation on these valves was never observed. Small fibrin thrombi with platelet adhesion, nevertheless, showed a tendency to become loosely attached to the tissue ingrowth inside the valve opening during the first six to eight weeks in the baboon in the absence of anticoagulants. It seems likely that the tissue that covers the prosthetic valves resulted from the deposition and dedifferentiation of circulating blood cells rather than a proliferation of atrial and ventricular wall endothelium. In the baboon it takes from 10 to 12 weeks for this tissue ingrowth to obtain a smooth surface while in the interim irregular fibrin and platelet adhesion occur resulting in the formation of small thrombi. These were non-infected thrombi and, although small, they may serve as a potential source of emboli. Braunwald and Bonchek (1967), using calves, did not observe similar fibrin thrombi in their animals that died or were sacrificed more than four weeks postoperatively and in whom tissue ingrowth had occurred.

Fibrin thrombi also occur in the human being in the absence of anticoagulants as shown in the patient who succumbed after two weeks. This point is further stressed by the early occurrence of embolism two to seven weeks post-operatively in three patients off anticoagulants in whom a Dacron velour covered mitral prosthesis was inserted. The fact that those patients in whom early anticoagulant therapy was instituted sustained no embolism seems to indicate that anticoagulant therapy may prevent the formation of fibrin thrombi and subsequent early embolism. Drugs known to reduce platelet adhesiveness and aggre- gation, possibly in conjunction with anticoagu踣 lants, might be beneficial and may warrant a triat in future. Although some do not advocate the use of anticoagulant therapy following prostheti mitral valve replacement (Effler, Favaloro, an£ Groves, 1965), we do not subscribe to this policyeo On the contrary, based on our experimental and clinical results, we strongly recommend the use of anticoagulants during the initial three to four postow operative months. Yeh, Anabtawi, Cornett, an Ellison (1967) also reported beneficial effects o⿶ adequate anticoagulant therapy following proș thetic mitral valve replacement.

After three months the valve ring, including the valve opening in the baboon, was covered bQ smooth endothelium without the presence of fibrin. thrombi. At this stage the smooth ingrowth of living tissue into the Dacron velour covering thu seems capable of preventing thromboembolism i the baboon. Should a similar tissue ingrowth intô the prosthetic covering occur in the human, th 9 likelihood of late thromboembolic episodes will bị diminished and it may be possible to discontinue the use of anticoagulants three to four month following surgery.

We wish to thank Professor A. J. Brink and Dहै A. R. Bosman for the catheterization studies and pos $\mathbb{R}$ operative assistance, Drs. M. A. de Kock and C. P Retief for the chemical and respiratory studies, Do P. Foster for administering anaesthesia to all patients

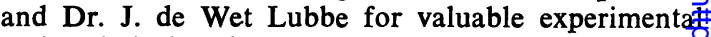
and technical assistance. The technical help of Mrs: A. Landman, Messrs. G. Mead, R. Cloete, and Df Jooste is greatly appreciated.

\section{REFERENCES}

Barnard, P. M., and Heydenrych, J. J. (1968). Tricuspid valve replacement with the University of Stellenbosch (US) and the University of Cape Town (UCT) prosthesis: An experimentäb study. S. Afr. med. J., 42, 250.

Mead, G., and Cloete, R. (1967). A new mitral valve prosthesis. A preliminary study (in Dutch). Ibid., 41, 52 .

Björk, V. O., and Malers, E. (1964). Total mitral valve replacement late result. J. thorac. cardiovasc. Surg., 48, 625.

Braunwald, N. S., and Bonchek, L. I. (1966). Controlled tissue i growth on prosthetic cardiac valves: A new means of preventin thromboembolism. Rev. Surg., 23, 300.

(1967). Prevention of thrombus formation on rigid proos thetic heart valves by the ingrowth of autogenous tissue. J. thorac. thetic heart valves by the ingroviovas. Surg., 54, 630 .
cardiovis

Cooley, D. A., Bloodwell, R. D., Beall, A. C., Gill, S. S., and Hallmant G. L. (1966). Total cardiac valve replacement using SCDKG Cutter prosthesis. Ann. Surg., 164, 428.

Den Otter, G. (1968). Total prosthetic replacement of atrioventriculat valves in the dog. Thorax, 23, 182.

Effler, D. B., Favaloro, R., and Groves, L. K. (1965). Heart val replacement. Clinical experience. Ann thorac. Surg., 1, 4. क

Schrire, V., and Barnard, C. N. (1966). An analysis of cardiac surgery at Groote Schuur Hospital, Cape Town, for the 14 years Aprit 1951-April 1965. S. Afr. med. J., 40, 279.

Starr, A. (1960). Total mitral valve replacement; fixation and throm bosis. Surg. Forum, 11, 258.

Herr, R. H., and Wood, J. A. (1967). Mitral replacemen Review of six years' experience. J. thorac. cardiovasc. Surg., 54, 33

Yeh, T. J., Anabtawi, I. N., Cornett, V. E., and Ellison, R. G. (1967) Influence of rhythm and anticoagulation upon the incidence of embolization associated with Starr-Edwards prostheses. Circula
tion, 35, Suppl. 1, p. 77 . 